\title{
Prevalensi hiperkolesterolemia pada remaja obes di Kabupaten Minahasa
}

\author{
${ }^{1}$ Felomina Jempormase \\ ${ }^{2}$ Widdhi Bodhi \\ ${ }^{2}$ Billy J. Kepel
${ }^{1}$ Kandidat Skripsi Fakultas Kedokteran Universitas Sam Ratulangi
${ }^{2}$ Bagian Kimia Fakultas Kedokteran Universitas Sam Ratulangi
Email: felominahesty@gmail.com

\begin{abstract}
Hypercholesterolemia is a risk factor for coronary heart diseases. Obesity is also a risk factor of hypercholesterolemia. This study aimed to determine the prevalence of hypercholesterolemia in obese adolescents in Tondano. This was a descriptive study with a cross sectional approach. Population was students of SMK Tondano from grade one to grade three aged 13 to 18 years. Samples were obtained by using simple random sampling. Weight, height, and cholesterol level were measured. There were 54 samples of obese students: 43 females (80\%) and 11 males (20\%). Of the 54 samples, 6 samples had elevated levels of cholesterol: 5 females (84\%) and 1 male (16\%). Conclusion: Obese females were more likely to have elevated levels of cholesterol compared to obese males.
\end{abstract}

Keywords: adolescents, obesity, cholesterol

\begin{abstract}
Abstrak: Hiperkolesterolemia merupakan salah satu faktor resiko penyebab terjadinya penyakit jantung koroner. Obesitas merupakan salah satu faktor resiko penyebab hiperkolesterolemia.Tujuan penelitian ini adalah untuk mengetahui prevalensi hiperkolesterolemia pada remaja obes di Kota Tondano. Penelitian ini menggunakan metode deskriptif dengan pendekatan potong lintang. Populasi ialah siswa SMK Negeri Kota Tondano dari kelas satu sampai kelas tiga yang berumur 13 sampai 18 tahun. Sampel diperoleh dengan teknik simple random sampling. Dilakukan pengukuran berat badan, tinggi badan dan pemeriksaan kadar kolesterol. Didapatkan 54 sampel siswa obes terdiri dari 43 siswi (80\%) dan 11 siswa (20\%). Dari 54 sampel yang diteliti, 6 sampel yang mengalami peningkatan kadar kolesterol yaitu 5 orang siswi $(84 \%)$ dan 1 orang siswa (16\%). Simpulan: Remaja perempuan yang obes lebih banyak mengalami peningkatan kadar kolesterol dibandingkan dengan remaja laki-laki yang obes.
\end{abstract}

Kata kunci: remaja, obesitas, kolesterol

Hiperkolesterolemia merupakan salah satu faktor resiko penyebab terjadinya penyakit jantung koroner. Di Indonesia saja, terdapat sekitar 36 juta penduduk atau sekitar 18\% dari penduduk Indonesia yang menderita kelainan lemak darah ini. Dari jumlah itu, $80 \%$ pasien meninggal mendadak akibat serangan jantung, dan 50\%-nya tidak menampakkan gejala sebelumnya. Kadar kolesterol pada orang dewasa dinyatakan tinggi apabila mencapai nilai $>240 \mathrm{mg} / \mathrm{dl}$ sedangkan pada anak-anak dan remaja nilai kolesterol total yang mencapai $200 \mathrm{mg} / \mathrm{dl}$ atau lebih sudah dinyatakan tinggi.

Obesitas adalah suatu penyakit serius yang mengakibatkan masalah emosional dan sosial. Seseorang dikatakan overweight bila berat badannya $10 \%$ samapi dengan 
$20 \%$ berat badan normal, sedangkan seseorang disebut obesitas apabila kelebihan berat badan mencapai lebih dari $20 \%$ berat badan normal. Menurut data RISKESDAS tahun 2007, prevalensi nasional obesitas umum pada penduduk usia 15 tahun keatas adalah 10,3\% (lakilaki 13,9\% dari perempuan 23,8\%).hal ini sejalan dengan hasil RISKESDAS 2010 yang menyebutkan bahwa prevalensi obesitas pada remaja (lebih dari 15 tahun) di Indinesia telah mencapai 19,1\%. Hal tersebut juga didukung oleh penelitian yang dilakukan di SMK Negeri Tondano dengan hasil pemeriksaan dari 110 siswa didapati yang obesitas sentral 42 siswa (38\%) yang terdiri dari laki-laki $14 \%$ dan perempuan $86 \%$.

\section{METODE PENELITIAN}

Penelitian ini bersifat cross sectional dengan pendekatan deskriptif.Penelitian ini dilakukan dari bulan Agustus2012 sampai Januari 2013, Waktu pengambilan data dilakukan dari bulan November 2012 sampai Januari 2013.Tempat penelitian pengambila sampel dilakukan di SMK Negeri 2 Tondano dan SMK Negeri 3 Tondano, Analisa sampel dilakukan di Laboratorium Manado. Populasi adalah siswa SMK yang berumur 13 sampai 18 tahun di Kota Tondano dan Sampel adalah siswa SMK Negeri 2 dan Negeri 3 yang obes di Kota Tondano. Analisa data yang diperoleh dikumpulkan, diolah dengan menggunakan program SPSS for Windows 20 selanjutnya ditampilkan dalam bentuk Tabel.

Tabel 1. Kadar kolestrol pada Remaja obes

\begin{tabular}{ccc}
\hline No & Jenis Kelamin & $\begin{array}{c}\text { Kadar Kolesterol } \\
\mathrm{mg} / \mathrm{dl}\end{array}$ \\
\hline 1 & $\mathrm{~L}$ & 57 \\
2 & $\mathrm{~L}$ & 56 \\
3 & $\mathrm{P}$ & 61 \\
4 & $\mathrm{P}$ & 87 \\
5 & $\mathrm{P}$ & 81 \\
6 & $\mathrm{P}$ & 70 \\
7 & $\mathrm{P}$ & 121 \\
8 & $\mathrm{P}$ & 97 \\
9 & $\mathrm{P}$ & 65 \\
\hline
\end{tabular}

\begin{tabular}{|c|c|c|}
\hline 10 & $\mathrm{P}$ & 125 \\
\hline 11 & $\mathrm{P}$ & 87 \\
\hline 12 & $\mathrm{P}$ & 113 \\
\hline 13 & $\mathrm{P}$ & 62 \\
\hline 14 & $\mathrm{P}$ & 75 \\
\hline 15 & $\mathrm{P}$ & 76 \\
\hline 16 & $\mathrm{P}$ & 74 \\
\hline 17 & $\mathrm{~L}$ & 76 \\
\hline 18 & $\mathrm{P}$ & 134 \\
\hline 19 & $\mathrm{P}$ & 80 \\
\hline 20 & $\mathrm{P}$ & 196 \\
\hline 21 & $\mathrm{P}$ & 149 \\
\hline 22 & $\mathrm{P}$ & 136 \\
\hline 23 & $\mathrm{P}$ & 95 \\
\hline 24 & $\mathrm{P}$ & 176 \\
\hline 25 & $\mathrm{P}$ & 62 \\
\hline 26 & $\mathrm{P}$ & 46 \\
\hline 27 & $\mathrm{~L}$ & 115 \\
\hline 28 & $\mathrm{P}$ & 80 \\
\hline 29 & $\mathrm{P}$ & 90 \\
\hline 30 & $\mathrm{P}$ & 94 \\
\hline 31 & $\mathrm{P}$ & 61 \\
\hline 32 & $\mathrm{P}$ & 207 \\
\hline 33 & $\mathrm{P}$ & 63 \\
\hline 34 & $\mathrm{P}$ & 78 \\
\hline 35 & $\mathrm{P}$ & 96 \\
\hline 36 & $\mathrm{P}$ & 78 \\
\hline 37 & $\mathrm{P}$ & 51 \\
\hline 38 & $\mathrm{P}$ & 85 \\
\hline 39 & $\mathrm{~L}$ & 216 \\
\hline 40 & $\mathrm{P}$ & 102 \\
\hline 41 & $\mathrm{P}$ & 102 \\
\hline 42 & $\mathrm{P}$ & 61 \\
\hline 43 & $\mathrm{P}$ & 158 \\
\hline 44 & $\mathrm{P}$ & 70 \\
\hline 45 & $\mathrm{~L}$ & 60 \\
\hline 46 & $\mathrm{~L}$ & 132 \\
\hline 47 & $\mathrm{~L}$ & 91 \\
\hline 48 & $\mathrm{~L}$ & 104 \\
\hline 49 & $\mathrm{~L}$ & 82 \\
\hline 50 & $\mathrm{~L}$ & 90 \\
\hline 51 & $\mathrm{P}$ & 168 \\
\hline 52 & $\mathrm{P}$ & 173 \\
\hline 53 & $\mathrm{P}$ & 248 \\
\hline 54 & $\mathrm{P}$ & 130 \\
\hline
\end{tabular}

Keterangan (American Academy of Pediatrics AAP 1998):

- Kadar kolesterol normal pada remaja :120-170 $\mathrm{mg} / \mathrm{dL}$

- Kadar kolesterol tidak normal pada remaja : $\geq 170 \mathrm{mg} / \mathrm{dL}$

\section{HASIL PENELITIAN}

Penelitian dilakukan sejak bulan 
Agustus 2012 hingga bulan Januari 2013 di SMK Negeri Kota Tondano. Pada awal penelitian peneliti terlebih dahulu membuat surat persetujuan penelitian yang ditandatangani oleh Kepala Dinas SMK Negeri di Kota Tondano untuk mendapatkan izin penelitian di Sekolah SMK Negeri Kota Tondano. Setelah mendapatkan izin, peneliti melakukan sosialisasi kepada siswa-siswi. Total seluruh siswa/i berjumlah 1677; siswa/i yang tidak berpartisipasi berjumlah 1282 sedangkan siswa/i yang berpartisipasi berjumlah 395. Didapatkan siswa obes berjumlah 104 dan siswa non-obes 291 siswa. Yang bersedia mengikuti pemeriksaan darah dan tekanan darah berjumlah 54 siswa/i dan yang tidak bersedia pemeriksaan darah dan tekanan darah berjumlah 50 siswa/i.

Populasi ialah siswa/i SMK Negeri Kota Tondano yang obes sebanyak 104 orang yang diambil dari kelas X,XI,XII SMK Negeri Kota Tondano. Dari 104 siswa tersebut diambil secara random dan didapatkan 54 siswa yang memenuhi kriteria inklusi dan eksklusi yang dijadikan sampel penelitian untuk dilakukan pemeriksaan kadar kolesterol dalam darah.

Berdasarkan Tabel 1 didapatkan yang mengalami peningkatan kadar kolesterol (Hiperkolesterolemia) berjumlah 6 orang (40\%) dari 15 siswa/i: 1 siswa (16\%) dan 5 siswi (84\%) sedangkan yang memiliki kadar kolesterol dalam batas normal berjumlah 9 orang (60\%) dari 15 siswa/i: 1 siswa (12\%) dan 8 siswi (88\%).

Tabel 3.1 Distribusi Kadar Kolesterol Menurut Jenis Kelamin pada siswa/i obes

\begin{tabular}{|c|c|c|c|c|c|c|}
\hline \multirow{3}{*}{$\begin{array}{c}\text { Jenis } \\
\text { Kelamin }\end{array}$} & \multicolumn{4}{|c|}{ Kadar Kolestrol } & \multirow{2}{*}{\multicolumn{2}{|c|}{ Total }} \\
\hline & \multicolumn{2}{|c|}{$>170 \mathrm{mg} / \mathrm{dL}$} & \multicolumn{2}{|c|}{$120-170 \mathrm{mg} / \mathrm{dL}$} & & \\
\hline & $\begin{array}{c}\text { Tidak } \\
\text { normal }\end{array}$ & $\%$ & Normal & $\%$ & Siswa/i & $\%$ \\
\hline Siswa & 1 & 16 & 1 & 12 & 2 & 14 \\
\hline Siswi & 5 & 84 & 8 & 88 & 13 & 86 \\
\hline Total & 6 & 100 & 9 & 100 & 15 & 100 \\
\hline
\end{tabular}

\section{BAHASAN}

Berdasarkan penelitian yang telah dilakukan di SMK Negeri Kota Tondano didapatkan bahwa sejumlah 104 siswa (26,32\%) mengalami obesitas dari 395 subjek penelitian. Angka ini cukup tinggi dalam menunjukan kejadian obesitas pada satu kelompok.

Obesitas merupakan kondisi kelebihan akumulasi lemak pada jaringan adipose tubuh.Penyebab tersimpannya lemak dalam tubuh adalah kelebihan pemasukan energy daripada yang dikeluarkan.Pada penderita obesitas, jumlah lemak yang tersimpan dalam tubuh besar.Normalnya seorang pria memiliki 12-20\% lemak dari berat badannya, sedangkan wanita memiliki 20$30 \%$ lemak dari berat badan.
Secara umum penyebab obesitas belum dapat diketahui secara pasti.Faktor keturunan dan lingkungan memberikan pengaruh yang berbeda kepada setiap orang. Faktor genetic mempengaruhi seseorang meningkat atau menurun berat badannya ketika ia kelebihan atau kekurangan asupan energi. Beberapa orang dapat menjadi obes bukan karena asupan energi berlebih, namun karena kurangnya aktifitas fisik.

Hiperkolesterolemia merupakan salah satu gangguan kadar lemak dalam darah (dyslipidemia) yang mana kadar kolesterol dalam darah lebih dari $240 \mathrm{mg} / \mathrm{dl}$. Beberapa faktor yang dapat menyebabkan seseorang beresiko tinggi hiperkolesterolemia adalah obesitas atau kegemukan, makanan tinggi 
asam lemak dan lemak jenuh biasanya makanan yang digoreng, makanan rendah serat, kurang beraktifitas fisik dan merokok.

Pada Tabel 1 prevalensi obesitas lebih meningkat pada remaja perempuan dengan jumlah 43 siswa (80\%) dibandingkan dengan laki-laki yang hanya berjumlah 11 siswa (20\%). Hasil ini berbanding lurus dengan data Riset Kesehatan Dasar (Riskesdas) pada tahun 2007, prevalensi obesitas pada penduduk berusia $\geq 15$ tahun berdasarkan IMT adalah 10,3\% (laki-laki 13,9\%) dan (perempuan 23,8\%). Perempuan dikatakan lebih muda mengalami obesitas akibat daripada kurangnya aktifitas fisik dibandingkan golongan laki-laki.

Tabel 1 juga menggambarkan kadar kolesterol pada remaja obes dengan jumlah 15 siswa (100\%) yang mengalami peningkatan kadar kolesterol (hiperkolesterolemia) terdiri dari 6 orang (12\%) yaitu siswi sebanyak 5 orang (84\%) dan siswa berjumlah 1 orang (16\%), sedangkan yang mempunyai kadar kolesterol dalam batas normal sebanyak 9 (60\%). Obesitas yang menetap selama periode waktu tertentu, kilokalori yang masuk melalui makanan lebih banyak dapatmenyebabkanterjadinya gangguan metabolik berupa hiperkolesterolemia. Kadar lemak yang abnormal dalam sirkulasi darah (terutama kolesterol) bisa menyebabkan masalah jangka panjang. Risiko terjadinya aterosklerosis dan penyakit arteri koroner meningkat pada seseorang yang memiliki kadar kolesterol total yang tinggi.

Di Indonesia, angka kejadian hiperkolesterolemia penelitian MONICA I (1988) sebesar 13,4\% untuk wanita dan 11,4\% untuk pria. Pada MONICA II (1994) didapatkan meningkat menjadi 16,2\% untuk wanita dan $14 \%$ pria. Prevalensi hiperkolesterolemia masyarakat pedesaan, mencapai 200-248 mg/dL atau mencapai 10,9 persen dari total populasi pada tahun 2004. Penderita pada generasi muda, yakni usia 25-34 tahun, mencapai 9,3\%. Wanita menjadi kelompok paling banyak menderita masalah ini, yakni $14,5 \%$, atau hampir dua kali lipat kelompok laki-laki.

\section{SIMPULAN}

Dari hasil penelitian yang dilakukan pada remaja di Kota Tondano yaitu siswa/i SMK Negeri di Kota Tondano dapat disimpulkan bahwa:

1. Prevalensi remaja yang mengalami obesitas sebanyak $26,32 \%$

2. Prevalensi remaja obes yang mengalami peningkatan kadar kolesterol (Hiperkolesterolemia) sebanyak $40 \%$

\section{DAFTAR PUSTAKA}

1. Dariyo A. Psikologi Perkembangan Remaja. Jakarta: Ghalia Indonesia, 2004.

2. Hurlock EB. Psikologi Perkembangan Suatu Pendekatan Sepanjang Rentang kehidupan (5th ed). Alih bahasa: Istiwidayanti, Soedjarwo. Jakarta: Erlangga,1980.

3. Kusumah. Diet Allah Rasullah. Jakarta: Quantum Media, 2007.

4. Sitepoe M. Kolesterol Fobia. Jakarta: Gramedia Pustaka Utama,1993.

5. Musa. Faktor Risiko Obesitas Pada Remaja. Available

from: http://www.pasca.undip.ac.id/index.p hp/20100227152/latestfaktor-risikoobesitas-pada-remaja-.html.Accesed on 11 may 2010

6. Supari F. Metabolic Syndrome in Jakarta. MKI. 2005;55(10):618-21.

7. Kemur EJ. Prevalensi sindrom metabolic pada remaja di Kota Tondano [Skripsi]. Manado: Universitas Sam Ratulangi; 2010.

8. Hafiza P. Kolesterol dan Lemak itu penting. Yogyakarta: Hanggar Kreator, 2011; p. 9-27.

9. Mu'tadin, Zainun. Obesitas dan Faktor Penyebab. Diakses 13 mei 2002. http://www.epsikologi.com/remaja/130502.htm

10.Nevid JS, Rathus AS, Greene B. Psikologi Abnormal (5th ed). Jakarta: Erlangga, 2005.

11. Yayasan Jantung Indonesia. Obesitas. 20032005. Available from: http://id.indheart.or.id/?p=37 
12.Grummer-Strawn LM, et al. Centre for Obesity Research and Education 2002-2007.

13.Aru WS, Bambang S, Idrus A, Marcellus S K, Siti S. Ilmu Penyakit Dalam jilid III (4th ed). Jakarta: Departemen Ilmu Penyakit Dalam FKUI; p. 1992.

14.Widyaloka CH. Hidup Sehat Tanpa Obesitas. Seminar Nasional. Universitas Brawijaya 4 maret 2002.

15.Krummel DA. Medical nutrion therapy for cardiovaskular disease. In: Mahan LK, Escott-stump S, editors. Krause's Food, Nutrion, and Diet Therapy (12th ed). USA: Saunders, 2008; p. 834-60.

16.http://jualherbalkolesterol.wordpress.com/2 011/03/23/komplikasi-hiperkolesterol-episode-2/

17.Konsensus Pengelolaan Dislipidemia di Indonesia. Perkumpulan Endrokinologi Indonesia (PERKENI), 2012; p. 31.

18.Sri D. Buku Pintar Kesehatan. Kolesterol, Diabetes dan Asam urat.Hal. 2-39

19.Mutiara S. Dahsyatnya Khasiat Jus untuk Kolesterol. Solusi sehat dengan jus buah dan sayuran.
20.Poppy K, Dyah N. Kamus saku kedokteran Dorland (25th ed). Edisi bahasa Indonesia. Jakarta: EGC, 1998.

21.Rodrig N. New Obesity Index is Now Recomended for Asia Pasific Medical News. 2003. Available from: www.amn.com.

22.Isomoko R. Acute effects of various fast food meals on vascular function and cardiovascular disease risk markers, Am J Clin Nutr. 2007;86:334-40.

23.Khomsan A. Pangan dan Gizi untuk Kesehatan. Jakarta: PT. Raya Gravindo Persada, 2003.

24.Badan penelitian dan pengembangan Depkes RI. Laporan Hasil Riset Kesehatan Dasar Nasional Tahun 2010. Jakarta; Departemen Kesehatan RI;2010http://doktermedis.blogspot.c om/2009/07/hiperkolesterolemiabagian1.htmlhttp://www.dexagroup.c om/newsandmedia/news/detail.php?id $\mathrm{c}=2$ \&id $=76$

25.Hernawati. Peranan Berbagai Sumber Serat dalam Dinamika Kolesterol Pada Individu hiperkolesterolemia dan normokolesterolemia. Bandung: FMIPA Universitas Pendidikan Indonesia. 